\title{
Fåhraeus and Fåhraeus-Lindqvist Effects for Neonatal and Adult Red Blood Cell Suspensions
}

\author{
COLIN B. MCKAY, OTWIN LINDERKAMP, AND HERBERT J. MEISELMAN
}

Department of Physiology and Biophysics /C.B.M., H.J.M.J. University of Southern California School of Medicine, Los Angeles, California 90033; Division of Neonatology /O.L.J. Department of Pediatrics, University of Heidelberg. Heidelherg, Germany; and Biomedical Engineering Laboratory /C.B.M.J. Rice University: Houston. Texas 77251

\begin{abstract}
In blood vessels with diameters less than $500 \mu \mathrm{m}$, both the hematocrit and viscosity decrease with decreasing tube diameter [Fåhraeus effect (FE) and Fåhraeus-Lindqvist effect (FLE)]. Because both effects may be influenced by red blood cell (RBC) volume and osmolality, the effects of RBC type and suspending medium osmolality $(216,294$, and $473 \mathrm{mosmol} / \mathrm{kg})$ on tube hematocrit $\left(\mathbf{H}_{\mathrm{T}}\right)$ and relative viscosity $\left(\eta_{\mathrm{r}}\right)$ in narrow tubes $(32$ to $145 \mu \mathrm{m}$ diameter) were studied for $0.40 \mathrm{~L} / \mathrm{L}(40 \%)$ hematocrit suspensions of human neonatal and adult RBC in buffer. Osmolality of $473 \mathrm{mosmol} / \mathbf{k g}$ caused shrinkage of RBC by $20 \%$ so that neonatal $R B C$ assume the volume of adult RBC in isotonic buffer. The FLE and FE were present for both neonatal and adult RBC suspensions regardless of osmolality. The viscosity reduction when going from a 145- to a 32- $\mu \mathrm{m}$ tube was greatest for the hypertonic neonatal and adult $\mathrm{RBC}$ : changes were $-44 \%(473$ mosmol $/ \mathrm{kg}$ ) and $-31 \%$ (294 mosmol $/ \mathrm{kg})$ for neonatal RBC, and $-39 \%$ (473 mosmol $/ \mathrm{kg}),-34 \%$ (294 mosmol $/ \mathrm{kg})$, and $-21 \%$ (216 mosmol/kg) for adult RBC. The $\eta_{\mathrm{r}}$ were significantly lower ( $7 \%$ on average) for isotonic neonatal RBC compared with adult cells in 32- $\mu \mathrm{m}(p<0.025), 46-\mu \mathrm{m}$, and $146-\mu \mathrm{m}$ tubes $(p<0.001)$. In contrast, $H_{\mathrm{T}}$ and thus the FE were less affected by RBC type or osmolality (only $13 \%$ change over entire range of osmolality and diameter): relative $\mathbf{H}_{\mathrm{T}}$ values were systematically lower $(p<0.02)$, and the FE greater, for isotonic neonatal versus adult RBC. At each osmolality, $\eta_{\mathrm{r}}$ increased linearly with increasing $H_{T}$. However, the viscosity- $H_{T}$ relations differed at various osmolalities. A semiempirical model indicated that 1) $\mathrm{H}_{\mathrm{T}}$, relative cell volume and thus mean cellular $\mathrm{Hb}$ concentration, and tube diameter are primary determinants of $\eta_{r}$, and 2) $\eta_{r}$ can be predicted for neonatal and adult RBC in hypertonic and isotonic media over a wide range of tube diameters. We conclude that the FLE and FE are more pronounced for neonatal RBC than for adult RBC. This cannot be explained by the increased volume of neonatal RBC, because shrunk RBC showed higher FLE than RBC in isotonic solution. Increased FLE and FE of neonatal RBC may facilitate blood flow in narrow vessels, particularly in vessels with high osmolality (i.e. renal vasa recta). (Pediatr Res 34: 538-543, 1993)
\end{abstract}

\section{Abbreviations}

FE, Fåhraeus effect

FLE, Fåhraeus-Lindqvist effect

Received January 25, 1993; accepted May 18, 1993.

Correspondence and reprint requests: Colin B. McKay, PhD, Biomedical Engineering Laboratory, P.O. Box 1892, Rice University, Houston, TX 77251-1892.

Supported by National Institutes of Health Grants HL 15722, HL 41341, and HL 48484, and by American Heart Association-Greater Los Angeles Affiliate Investigative Group Award 5371G.
$\mathrm{H}_{\mathrm{T}}$, tube hematocrit

MCHC, mean cellular $\mathrm{Hb}$ concentration

RBC, red blood cell

$V$, volume of $R B C$ suspended in media of experimental osmolality

$V_{\text {iso, }}$ volume of $R B C$ in isotonic media

$\eta_{r}$, relative viscosity of $R B C$ suspensions

$\mathrm{H}_{\mathrm{D}}$, discharge hematocrit

$\mathrm{H}_{\mathrm{F}}$, feed hematocrit

$\mathrm{H}_{\mathrm{T}} / \mathrm{H}_{\mathrm{F}}$, relative tube hematocrit

rms, root mean square

Blood and oxygen are supplied to tissue via the microcirculation, and thus their delivery is influenced by the resistance to flow of the microcirculation. Microvascular flow resistance is determined by vascular resistance and blood viscosity, with blood viscosity influenced by hematocrit, blood cell deformability, and the diameter of the microvessels $(1,2)$. Normal adult blood flowing in narrow vessels and tubes exhibits anomalous rheologic behavior: both the apparent viscosity and the hematocrit of the flowing blood (i.e. the $\mathrm{H}_{\mathrm{T}}$ ) decrease with decreasing tube diameter (3-9). These phenomena are commonly termed the FLE, the decrease in apparent viscosity (10), and the FE, the decrease in $\mathrm{H}_{\mathrm{T}}(11,12)$. In addition, $\mathrm{RBC}$ mechanical and geometric properties (e.g. RBC deformability) may be expected to have an effect on blood flow in small tubes and microvessels, since cellular behavior can influence cell-cell interactions in tube flow $(12,13)$.

$\mathrm{RBC}$ deformability (i.e. the ability of the RBC to adopt a new shape in response to deforming forces) is an important determinant of blood flow in narrow tubes and pores (14) and is affected by cell shape, cell size, membrane mechanical properties and cytoplasmic viscosity (12, 15-17). In general, RBC deformability decreases as the resting morphology deviates from the biconcave shape, as the membrane surface area-to-volume ratio decreases, as the membrane becomes more rigid, and/or as the cytoplasmic viscosity increases $(14,16,17)$. McKay and coworkers $(18,19)$ have reported that $\mathrm{RBC}$ made rigid, via treatment with glutaraldehyde or by heat, maintain their resting biconcave shape and volume yet exhibit: $I$ ) a sharp "reversal" in the FLE, with viscosity increasing as tube diameter decreases below about 150 $\mu \mathrm{m}$; and 2) a reduction in the FE (i.e. less reduction of tube hematocrit). Braasch and Jenett (13) found increased viscosities for suspensions of RBC with crenated, echinocytic shapes, but did not provide data for the FE. Recently, McKay and Meiselman (20) have presented data for the effects of osmolality on the flow behavior of $0.40 \mathrm{~L} / \mathrm{L}(40 \%)$ hematocrit adult RBC suspensions flowing in $33-146 \mu \mathrm{m}$ tubes. Their results indicated that: l) viscosity increased markedly for hypertonically shrunk RBC: 2) the FLE increased monotonically with increasing hyperton- 
icity (i.e. viscosity more sensitive to tube diameter at higher osmolalities), with no reversal of the FLE over the range 166$836 \mathrm{mosmol} / \mathrm{kg}$; 3) $\mathrm{H}_{\mathrm{T}}$ was insensitive to hypertonicity for tubes $\geq 86 \mu \mathrm{m}$, and increased significantly with decreasing $\mathrm{RBC}$ volume for diameters $\leq 46 \mu \mathrm{m}$; and 4 ) for hypotonically swollen $R B C$, viscosity decreased slightly and was insensitive to hypotonicity and tube diameter, whereas $\mathrm{H}_{\mathrm{T}}$ was decreased for tubes $\leq 46$ $\mu \mathrm{m}$. Therefore, the FLE and FE exhibit opposite responses to changes of RBC volume (20). RBC deformability thus has a major effect on adult blood flow in narrow tubes, especially when tube diameter approaches the size of the cell.

Neonatal and adult RBC have many similar characteristics that affect erythrocyte deformability. In particular, both red cell types have a biconcave shape at rest, and no significant differences for membrane surface viscosity or $\mathrm{MCHC}$; isotonic $\mathrm{MCHC}$ values of $32.6 \pm 0.3 \mathrm{~g} / \mathrm{dL}(326 \pm 3 \mathrm{~g} / \mathrm{L})$ for neonates and 33.0 $\pm 0.2 \mathrm{~g} / \mathrm{dL}(330 \pm 2 \mathrm{~g} / \mathrm{L})$ for adults (mean \pm SEM) have been reported by Linderkamp et al. (21). Further, membrane-free $\mathrm{Hb}$ solutions prepared from neonatal and adult $\mathrm{RBC}$ exhibit identical viscosities when tested at a Hb concentration of $33 \mathrm{~g} / \mathrm{dL}(330$ $\mathrm{g} / \mathrm{L})(21)$. However, neonatal RBC are significantly larger than adult cells (i.e. $11 \%$ greater diameter, $13 \%$ greater surface area, $20 \%$ larger volume), and thus require greater negative pressures to enter small micropipettes $(21,22)$; conversely, neonatal $\mathrm{RBC}$ have a slightly less rigid membrane (21). Given the marked geometric differences between neonatal and adult RBC, it would be expected that their flow behavior would also differ $(1,12)$. Nevertheless, there are relatively few reports germane to neonatal RBC flow in small tubes and pores: 1 ) data for bulk suspension viscosity and micropore flow for normal neonatal blood and neonatal $\operatorname{RBC}(23,24)$ indicate sensitivity to cell volume; and 2) reduced viscosity for neonatal $\mathrm{RBC}$ suspensions in $50-\mu \mathrm{m}$ tubes has been reported (25), but data for $\mathrm{H}_{\mathrm{T}}$ (i.e. the FE) were not presented. It is therefore likely that the FE and FLE may be sensitive to the geometry of the neonatal RBC.

The present study was thus designed to 1) extend the earlier studies of viscosity and $\mathrm{H}_{\mathrm{T}}$ for adult red cells $(20,26)$ to $0.40 \mathrm{~L} /$ $\mathrm{L}(40 \%)$ hematocrit suspensions of neonatal RBC in 32- to 146$\mu \mathrm{m}$ diameter tubes, and 2 ) evaluate the role of cellular geometry and deformability by comparing data for isotonic neonatal cells with hypertonic suspensions of neonatal cells shrunk to the same volume as normal adult red cells. Moreover, adult $\mathrm{RBC}$ were swollen in hypotonic media to the same volume as normal neonatal RBC. Our results indicate that neonatal RBC have lower viscosity and hematocrit (i.e. greater $\mathrm{FE}$ ) in narrow tubes compared with adult cells. Our results on shrunk neonatal RBC and swollen adult cells do not support the hypothesis that the favorable rheologic properties of neonatal $\mathrm{RBC}$ result solely from their large volume

\section{MATERIALS AND METHODS}

Blood and RBC suspensions. Placental blood samples from seven healthy, full-term newborn infants with birth weights of $3400-3700 \mathrm{~g}$ were studied with approval of the University of Southern California Human Subjects Research Committee. Immediately after cord clamping, $10 \mathrm{~mL}$ of blood were collected from the placenta into heparin $(5 \mathrm{IU} / \mathrm{mL})$. All $\mathrm{RBC}$ preparations and rheologic measurements were carried out at room temperature $\left(21 \pm 0.1^{\circ} \mathrm{C}\right)$ within $8 \mathrm{~h}$ after collection. $\mathrm{RBC}$ were isolated by centrifugation at $2000 \times g$ for $10 \mathrm{~min}$ and the plasma and buffy coat removed by gentle aspiration. The cells were washed twice, via centrifugation-aspiration, in the final suspending media, which were PBS solutions $\left(0.03 \mathrm{M} \mathrm{KH}_{2} \mathrm{PO}_{4}+\mathrm{Na}_{2} \mathrm{HPO}_{4}\right.$, $\mathrm{pH} 7.4$ at $25^{\circ} \mathrm{C}$ ); all PBS solutions contained $2 \mathrm{~g} / \mathrm{L}$ human serum albumin (American Red Cross). The osmolalities of these PBS solutions were preadjusted to 294 and $473 \mathrm{mosmol} / \mathrm{kg}$ via addition of different quantities of $\mathrm{NaCl}$. For the hypertonic suspensions, the centrifugation force was reduced to $100 \times g$ to facilitate resuspension of the cells; RBC washed in nonisotonic PBS were allowed to equilibrate for $20 \mathrm{~min}$ between successive washes. After the second wash, cell suspensions at a hematocrit of 0.40 $\pm 0.002 \mathrm{~L} / \mathrm{L}(40 \pm 0.2 \%)$ were prepared by appropriate combination of packed $\mathrm{RBC}$ and the suspending medium.

Adult RBC suspension flow data presented herein are from previous reports from this laboratory $(20,26)$. Adult blood samples were collected from hematologically normal laboratory personnel via venipuncture into heparin, with the red cells washed and suspended in PBS having osmolalities of 216, 294. or $473 \mathrm{mosmol} / \mathrm{kg}$. All RBC preparation methods, experimental procedures, and methods of analysis for adult RBC were identical to those described for neonatal cells.

Relative $\mathrm{RBC}$ volumes, $\mathrm{V} / \mathrm{V}_{\text {iso, }}$, were calculated from the equation $(20,26)$ :

$$
\mathrm{V} / \mathrm{V}_{\text {iso }}=0.575\left(\mathrm{~T}_{\mathrm{iso}} / \mathrm{T}\right)+0.439
$$

where $\mathrm{V}$ and $\mathrm{V}_{\text {iso }}$ are cell volumes at the nonisotonic (T) and isotonic $\left(T_{\text {iso }}\right)$ osmolalities. Preliminary studies indicated that this equation was valid for neonatal cells (data not shown). Using this equation, calculated values of $\mathrm{V} / \mathrm{V}_{\text {iso }}$ are 1.22 at 216 mosmol $/ \mathrm{kg}$ and 0.80 at $473 \mathrm{mosmol} / \mathrm{kg}$. Thus, given the $20 \%$ larger isotonic volume of neonatal $\operatorname{RBC}(21,22)$, adult $R B C$ in $216 \mathrm{mosmol} / \mathrm{kg}$ PBS swell to the isotonic neonatal $\mathrm{RBC}$ volume, whereas neonatal $\mathrm{RBC}$ in $473 \mathrm{mosmol} / \mathrm{kg}$ shrink to the isotonic adult RBC volume. Note, however, that at equal values of

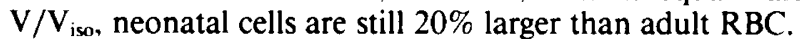

Experimental apparatus and procedures. The experimental viscometric system was identical for the neonatal and adult $R B C$ suspensions and has been described in detail elsewhere $(20,26)$. Briefly, the microcapillary viscometer consisted of a thick-walled glass tube (length $\approx 6.5 \mathrm{~cm}$ ) that was inserted horizontally into a small feed reservoir $(\approx 1.3 \mathrm{~mL}$ capacity); the $\mathrm{RBC}$ suspension inside the feed reservoir was gently stirred $(60 \mathrm{rpm})$ by a magnetic stir bar at the bottom of the reservoir. Tube diameters of approximately $30,50,90$, and $150 \mu \mathrm{m}$ were used, with the actual tube diameter determined by calibration (see below). Tubes of $340-\mu \mathrm{m}$ diameter were also used to obtain flow data that were unaffected by the FLE and FE $(3,4,6,7,10,11)$; for these large tubes only, various feed reservoir hematocrits of less than 0.40 $\mathrm{L} / \mathrm{L}(40 \%)$ were used to provide a range of $\mathrm{H}_{\mathrm{T}}$. The pressure drop across the tube, $\Delta \mathrm{P}$, and volumetric flow rate from the reservoir through the tube, $\mathrm{Q}$, were continuously monitored using a pressure transducer and a variable-speed syringe pump. The voltage controlling the speed of the syringe pump, and thus the volumetric flow rate $\mathrm{Q}$, was rapidly increased by use of an electronic flow controller $(20,26)$ until the required pressure drop $\Delta \mathbf{P}$ was achieved and then maintained to keep $\Delta \mathrm{P}$ constant.

Pressure drop and volumetric flow rate were simultaneously recorded via a chart recorder and the final values of these parameters determined after $5 \mathrm{~min}$ of stable flow; data from which the flow was unstable were discarded. For each tube diameter-RBC suspension set, pressure-flow data were obtained for at least four wall shear stresses in the range of 23 to 337 dyne $/ \mathrm{cm}^{2}$, where wall shear stress is proportional to pressure drop per unit tube length times tube diameter (see below). Note that before use with an RBC suspension, the linearity of the flow resistance (i.e. $\Delta \mathrm{P} / \mathrm{Q}$ ) per unit length of each tube was verified (coefficient of variation less than $0.6 \%$ ) using PBS over a wide range of pressure drops. Thus, viscometric artifacts were deemed to be absent (27).

Three separate hematocrits were measured via high-speed centrifugation $(12000 \times g)$ and a low-power optical microscope as previously described $(20,26): 1)$ The $H_{D}$ was determined in triplicate from samples of the RBC suspension leaving the discharge (outflow) end of the tube by collection into $5-\mu \mathrm{L}$ glass pipettes during a period of stable flow. The measured $H_{D}$ were then averaged to give the mean $H_{D}$ for a given tube-suspension set. 2) $T$ he $H_{F}$ of the RBC suspension inside the reservoir, $H_{F}$, was similarly measured for later comparison with $H_{D}$. 3) The hematocrit of the suspension flowing in the tube, $\mathrm{H}_{\mathrm{T}}$, was deter- 
mined by a "stopped flow" technique described previously by McKay and coworkers $(19,20,26)$. Here, the discharge end of the tube is sealed with a quick-setting resin while simultaneously halting the steady flow through the tube by rapidly stopping the syringe pump. The tube and trapped suspension were then removed from the reservoir, centrifuged, and the $\mathrm{H}_{\mathrm{T}}$ measured. This procedure was repeated in triplicate for each $\mathrm{RBC}$ suspension, then averaged and used to compute relative $\mathrm{H}_{\mathrm{T}}$ as the ratio $\mathrm{H}_{\mathrm{T}} / \mathrm{H}_{\mathrm{F}}$. Note that the packing efficiency of isotonic adult $\mathrm{RBC}$ is $0.975 \pm 0.008$ (SEM) and is independent of osmolality over the range of $166-836 \mathrm{mosmol} / \mathrm{kg}(20,26)$. Isotonic neonatal and adult RBC have similar packing efficiencies (21); thus, given the high deforming forces involved during the $12000 \times g$ centrifugation, neonatal and adult RBC at $473 \mathrm{mosmol} / \mathrm{kg}$ were assumed to have the same packing efficiency. Therefore, neither $\mathrm{H}_{D}, \mathrm{H}_{F}$, nor $\mathrm{H}_{\mathrm{T}}$ was corrected for trapped PBS in the $\mathrm{RBC}$ column.

Methods of analysis. The inside diameter, D, of each tube of measured length $\mathrm{L}$ was calculated via the Poiseuille relationship (27), using the mean value of $\triangle P / Q$ obtained from the $P B S$ calibration and the viscosity of PBS (assumed to be that of water as obtained from standard sources) at the temperature used for calibration. Wall shear stress $\left(\tau_{w}\right)$, the force per unit area at the tube wall resulting from the pressure gradient, was calculated via the standard equation $\tau_{W}=\Delta \operatorname{PD} / 4 \mathrm{~L}(20,26,27)$. The influence of flow rate on the rheologic behavior of the suspensions was characterized by the use of a power law model, $\tau_{\mathrm{W}}=k(U / D)^{\mathrm{N}}$, where $U$ is the average flow velocity and $U / D$ is the reduced average velocity of flow in the tube (i.e. an index to the wall shear rate). $\mathrm{N}$ has a value of unity for newtonian fluids and is less than unity for nonnewtonian fluids whose viscosity decreases with increasing U/D or with increasing $\tau_{\mathrm{w}}(27)$. An effective apparent viscosity was calculated for the RBC suspensions, at each $\Delta P$ level, using the Poiseuille relation $(20,26,27): \eta_{\mathrm{a}}=(\pi /$ $128)\left(D^{4} / \mathrm{L}\right)(\Delta \mathrm{P} / \mathrm{Q})$. Note that all effective apparent viscosity data were adjusted to $\tau_{\mathrm{W}}=9.0 \mathrm{~Pa}\left(90\right.$ dyne $\left./ \mathrm{cm}^{2}\right)$ and that all viscosity data are expressed as $\eta_{\mathrm{r}}$ (i.e. $\eta_{\mathrm{r}}=$ effective apparent viscosity of $\mathrm{RBC}$ suspension/viscosity of water at $20^{\circ} \mathrm{C}$ ).

Miscellaneous techniques. Buffer osmolalities were determined to $\pm 1 \mathrm{mosmol} / \mathrm{kg}$ by freezing-point depression (model 2007, Precision Instruments, Natick, MA) and $\mathrm{pH}$ via a radiometer system (model 2007, Radiometer, Copenhagen, Denmark) operating at $25^{\circ} \mathrm{C}$. Statistical differences between mean values were analyzed by the two-tailed $t$ test, and correlations between variables by least-squares linear regression and the Pearson correlation coefficient.

\section{RESULTS AND DISCUSSION}

General data. Several general experimental observations are relevant to the main body of data obtained in the present study.

Tube diameters determined by PBS calibration were $32.0 \pm$ $0.2,45.9 \pm 1.2,86.5 \pm 0.0$, and $145.4 \pm 0.1 \mu \mathrm{m}$ (mean \pm SEM from at least eight separate tubes in each nominal size group); in the subsequent text and figures, these diameters are termed 32 , 46,86 , and $145 \mu \mathrm{m}$. The wall shear stresses, calculated from the calibrated diameters and measured lengths, ranged from 23 to $84 \mathrm{dyne} / \mathrm{cm}^{2}(32 \mu \mathrm{m}), 23$ to $131 \mathrm{dyne} / \mathrm{cm}^{2}(46 \mu \mathrm{m}), 47$ to 229 dyne $/ \mathrm{cm}^{2}(86 \mu \mathrm{m})$, and 46 to $337 \mathrm{dyne} / \mathrm{cm}^{2}(145 \mu \mathrm{m})$.

Linear regressions of pressure drop-flow rate data, as $\log \tau_{W}$ versus $\log \mathrm{U} / \mathrm{D}$, were used to determine the exponent $\mathrm{N}$ of the above-mentioned power law model (see Materials and Methods). Because the resulting exponents were not meaningfully influenced by either tube diameter or osmolality, the data were pooled to yield a composite value $\mathrm{N}=0.952 \pm 0.013$ (SEM) for the neonatal $\mathrm{RBC}$ and $\mathrm{N}=0.957 \pm 0.010$ for the adult $\mathrm{RBC}$ (eight separate measurements evenly distributed over the range of diameter and osmolality for the neonatal and the adult cells). Both composite values differ from unity $(p<0.001)$, indicating that the neonatal and adult cell suspensions behaved as nonnewtonian fluids. However, because the exponents are very close to unity, the calculated change in apparent viscosity, over the entire range of $\tau_{w}$ (i.e. 23 to $337 \mathrm{dyne} / \mathrm{cm}^{2}$ ), is $<10 \%$. Nevertheless, to eliminate this small influence of shear stress, all apparent viscosity values were adjusted to $\tau_{\mathrm{w}}=9.0 \mathrm{~Pa}\left(90 \mathrm{dyne} / \mathrm{cm}^{2}\right)$ via the use of the log-log regression obtained for each tube-suspension data set.

Mean $\mathrm{H}_{\mathrm{F}}$ for the neonatal $\mathrm{RBC}$ suspensions was $0.401 \pm 0.002$ $\mathrm{L} / \mathrm{L}$ (SEM) from 32 separate measurements in all nominal tube diameter groups, and $0.400 \pm 0.007 \mathrm{~L} / \mathrm{L}$ for the adult $\mathrm{RBC}$ suspensions (20). $\mathrm{H}_{\mathrm{D}} / \mathrm{H}_{\mathrm{F}}$ was independent of media osmolality $(p>0.1)$ for both neonatal and adult $\mathrm{RBC}$ suspensions. For the $32-\mu \mathrm{m}$ tubes, the mean value $\mathrm{H}_{\mathrm{D}} / \mathrm{H}_{\mathrm{F}}$ for the 473 and 294 mosmol $/ \mathrm{kg}$ suspensions of neonatal $\mathrm{RBC}$ was $1.003 \pm 0.004$ (SEM, $p>0.1$ when tested versus unity), and did not significantly differ $(p>0.1)$ from $0.997 \pm 0.007$ reported earlier for adult $\mathrm{RBC}$ suspensions at $216-473 \mathrm{mosmol} / \mathrm{kg}(20,26)$. Similar nonsignificant results were obtained for the larger-diameter tubes. Therefore, "screening" effects (6), which may limit RBC entry into small-diameter tubes, were absent and not influenced by either osmolality or red cell type.

$\eta_{r}$-osmolality effects. The $\eta_{\mathrm{r}}$ versus tube diameter data for neonatal and adult RBC suspensions as a function of $\mathrm{V} / \mathrm{V}_{\text {iso }}$ are shown in Figure 1, where $V / V_{\text {iso }}$ values of $0.80,1.00$, and 1.22 correspond to media osmolalities of 473, 294, and 216 mosmol/ $\mathrm{kg}$, respectively. Inspection of these results indicates the following: l) Reductions of $\eta_{\mathrm{r}}$ with decreasing tube diameter (i.e. the FLE) were observed for both neonatal and adult RBC suspensions at all $\mathrm{V} / \mathrm{V}_{\text {iso }}$ levels. 2) In general, the absolute values of $\eta_{\mathrm{r}}$ increase with increasing medium osmolality (i.e. with decreasing $\left.\mathrm{V} / \mathrm{V}_{\text {iso }}\right)$, although the data for $\mathrm{V} / \mathrm{V}_{\text {iso }}=1.00$ and 1.22 tend to converge for 32- and $46-\mu \mathrm{m}$ tubes. 3) On average, the $\eta_{\mathrm{r}}$ of isotonic neonatal $\mathrm{RBC}$ was $7 \%$ lower than adult cells $(p<0.025$ or $p<0.001) .4$ ) The $\eta_{\mathrm{r}}$ of neonatal and adult RBC were similar over the entire range of tube diameter when suspended in the $473 \mathrm{mosmol} / \mathrm{kg}$ hypertonic medium. Lower $\eta_{\mathrm{r}}$ and a more pronounced FLE for neonatal $\mathrm{RBC}$ in $50-\mu \mathrm{m}$ tubes have also been reported by Zilow and Linderkamp (25); they speculated that this could be due to a greater hematocrit reduction in the
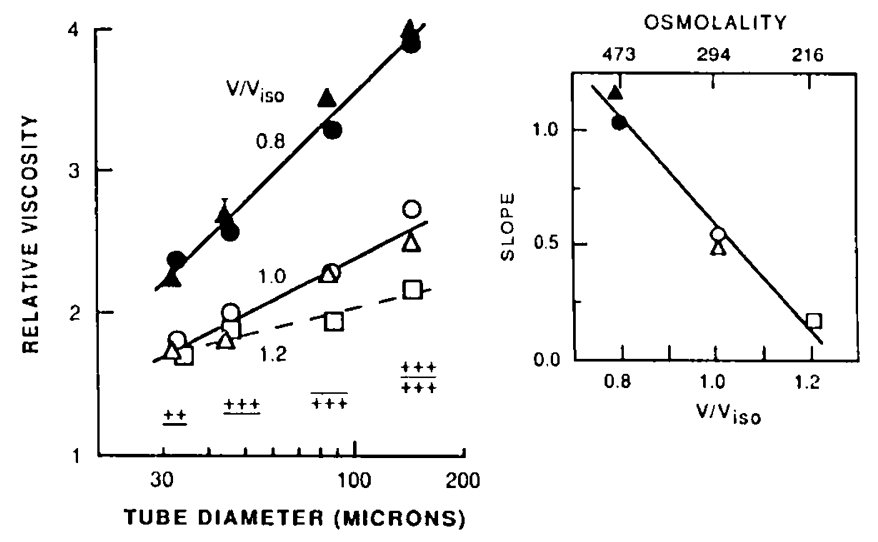

Fig. 1. The $\eta_{\mathrm{r}}$-tube diameter data for neonatal $\mathrm{RBC}$ at $\mathrm{V} / \mathrm{V}_{\text {iso }}=0.80$ and $1.00\left(\Delta\right.$ and $\triangle$, respectively), and adult $R B C$ at $V / V_{\text {iso }}=0.80,1.00$, and $1.22(\bullet, O$, and $\square$, respectively). The graph on the right presents the slopes of the $\eta_{\mathrm{r}}$-tube diameter relations for the various RBC suspensions obtained by linear regression, which increase monotonically with decreasing $\mathrm{V} / \mathrm{V}_{\text {iso }}$ for both cell types. FLE was more pronounced for hypertonic suspensions, whereas it was reduced for $R B C$ in isotonic or hypotonic media. Significance levels comparing isotonic neonatal with isotonic or hypotonic adult $\mathrm{RBC}$ viscosities are indicated in the graph on the left (above horizontal rule: isotonic neonatal $v s$ isotonic adult; below horizontal rule: isotonic neonatal $v$ hypotonic adult);,$++ p<0.025 ;+++, p<$ 0.001 . Viscosity data are mean \pm SEM from six separate studies; where not shown. error bars lie within symbols. All $\eta_{r}$ data in this and subsequent figures were adjusted to a wall shear stress $\left(\tau_{\mathbf{W}}\right)$ of $9.0 \mathrm{~Pa}$ ( 90 dyne/ $\mathrm{cm}^{2}$ ) (see Materials and Methods). 
tube (i.e. greater FE) for the neonatal cells, but did not present $\mathrm{H}_{\mathrm{T}}$ data.

To quantitate the effects of $V / V_{\text {iso }}$ on the magnitude of the FLE, the slopes of the $\eta_{\mathrm{r}}$-tube diameter relations for the various suspensions shown in Figure 1 were plotted versus $\mathrm{V} / \mathrm{V}_{\text {iso. As }}$ indicated by the insert in Figure 1 , the FLE increased strongly with decreasing $\mathrm{V} / \mathrm{V}_{\text {iso }}$ (i.e. with increasing osmolality): a $20 \%$ reduction of $\mathrm{V} / \mathrm{V}_{\text {iso }}$ from 1.00 to 0.80 caused a 2-fold increase in the FLE. Because a single line adequately describes the data shown in Figure 1 (right graph), and because at any $V / V_{\text {iso }}$ neonatal $\mathrm{RBC}$ are still $20 \%$ larger than adult $\mathrm{RBC}(22)$, these results suggest that intrinsic cellular deformability factors $(e . g$. $\mathrm{MCHC}$ and thus cytoplasmic viscosity) may dominate over cell size in determining resistance to flow for both cell types. That is, MCHC varies inversely with $\mathrm{V} / \mathrm{V}_{\text {iso }}$ (e.g. a $20 \%$ decrease of $\mathrm{V} / \mathrm{V}_{\text {iso }}$ yields a $20 \%$ increase of $\mathrm{MCHC}$ ). Because neonatal and adult $\mathrm{RBC}$ have identical isotonic MCHC levels (21), they will also have equal MCHC values, and therefore cytoplasmic viscosities, at any $\mathrm{V} / \mathrm{V}_{\text {iso }}$ : a $20 \%$ increase in MCHC from $33 \mathrm{~g} / \mathrm{dL}(330$ $\mathrm{g} / \mathrm{L}$ ) increases $\mathrm{Hb}$ viscosity by nearly 3 -fold, whereas a $20 \%$ decrease of MCHC lowers solution viscosity by about $50 \%$ (28). Note that the results presented in the Figure 1 insert are not consistent with the findings of Pries et al. (9), who indicate that the diameter dependence of viscosity is related to the cell-to-tube diameter ratio. However, the FLE is also affected by $\mathrm{H}_{\mathrm{T}}(4,5,7$, 11) and thus variations of $\mathrm{H}_{\mathrm{T}}$ must also be considered (see below).

$H_{T} / H_{t}$-osmolality effects. $\mathrm{H}_{\mathrm{T}} / \mathrm{H}_{\mathrm{F}}$ versus tube diameter data for neonatal and adult RBC suspensions are presented in Figure 2; note that $\mathrm{H}_{\mathrm{T}} / \mathrm{H}_{\mathrm{F}}$ values were consistently lower $(p<0.2)$ for isotonic neonatal versus adult cells. $\mathrm{H}_{\mathrm{T}} / \mathrm{H}_{\mathrm{F}}$ decreased with decreasing tube diameter (i.e. $\mathrm{FE}$ ) for both neonatal and adult $\mathrm{RBC}$ at all suspending media osmolalities: the mean slope of linear regression lines for the five types of suspensions shown was 0.071 $\pm 0.005(p<0.001$ when tested versus zero). However, as is evident from Figure 2, the magnitude of the FE was a function of cell type and $\mathrm{V} / \mathrm{V}_{\text {iso: }}:$ l) Isotonic neonatal $\mathrm{RBC}$ exhibited the largest reduction in $\mathrm{H}_{\mathrm{T}} / \mathrm{H}_{\mathrm{F}}$ (i.e. the greatest $\mathrm{FE}$ ), decreasing $13 \%$ from $0.911 \pm 0.003$ in $145-\mu \mathrm{m}$ tubes to $0.793 \pm 0.004$ in $32-\mu \mathrm{m}$ tubes (mean \pm SEM from $n=6$ experiments, $p<0.001$ ). 2) $\mathrm{H}_{\mathrm{T}} /$ $\mathrm{H}_{\mathrm{F}}$ values were largest and in close agreement for neonatal and adult $\mathrm{RBC}$ at $\mathrm{V} / \mathrm{V}_{\text {iso }}=0.80$, whereas the isotonic neonatal $\mathrm{RBC}$ data agreed well with those for adult cells swollen to the volume of isotonic neonatal $\mathrm{RBC}$ (i.e. with adult $\mathrm{RBC}$ at $\mathrm{V} / \mathrm{V}_{\text {iso }}=1.22$ ).

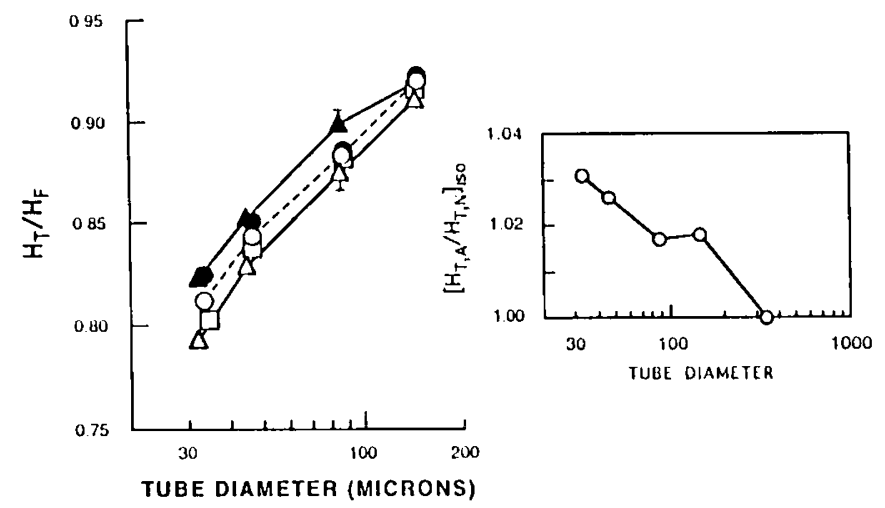

Fig. 2. $\mathrm{H}_{\mathrm{T}} / \mathrm{H}_{\mathrm{F}}$-tube diameter data for neonatal $\mathrm{RBC}$ at different values of $\mathrm{V} / \mathrm{V}_{\text {ison }}$; symbols and $\mathrm{V} / \mathrm{V}_{\text {iso }}$ values are identical to those shown in Figure 1. The FE was present for both neonatal and adult RBC at all osmolalities, but its magnitude for a given cell type decreased with decreasing $\mathrm{V} / \mathrm{V}_{\text {iso. }}$. The graph on the right presents the ratio of $\mathrm{H}_{\mathrm{T}}$ for isotonic adult $\mathrm{RBC}$ to $\mathrm{H}_{\mathrm{T}}$ for isotonic neonatal cells vs tube diameter. The increase of this ratio above 1.0 with decreasing tube diameter indicates an enhanced FE for neonatal RBC is adult cells. Relative $\mathrm{H}_{\mathrm{T}}$ data are mean \pm SEM from six separate studies; where not shown, error bars lie within symbols.
Intermediate values of $\mathrm{H}_{\mathrm{T}} / \mathrm{H}_{\mathrm{F}}$ were obtained for adult $\mathrm{RBC}$ in isotonic PBS. Note that the $\mathrm{H}_{\mathrm{T}} / \mathrm{H}_{\mathrm{F}}$ data for isotonic adult $\mathrm{RBC}$ shown in Figure 2 are in good agreement with literature values (2, 3, 7, 19), and that the convergence of $\mathrm{H}_{\mathrm{T}} / \mathrm{H}_{\mathrm{F}}$ with increasing tube diameter is unlike the marked divergence of apparent viscosity with tube size (Fig. 1). Thus, the FE and FLE exhibit opposite responses to changes of $\mathrm{RBC}$ volume.

The ratio of $\mathrm{H}_{\mathrm{T}}$ for isotonic adult cells to that for isotonic neonatal cells was greater than 1.0 in $145-\mu \mathrm{m}$ tubes and increased with decreasing tube diameter (Fig. 2, right graph), thereby suggesting that cell size dominates over $\mathrm{MCHC}$ in determining the FE. In contrast, the FLE was dominated by $\mathrm{MCHC}$ rather than cell size (Fig. 1). Note that for both neonatal and adult $\mathrm{RBC}$, tube diameter had much less of an effect on $\mathrm{H}_{\mathrm{T}} / \mathrm{H}_{\mathrm{F}}$ than on apparent viscosity, in that the maximum decrease noted for $\mathrm{H}_{\mathrm{T}} / \mathrm{H}_{\mathrm{F}}$ over the entire range of tube diameter and $\mathrm{V} / \mathrm{V}_{\text {iso }}$ was only $13 \%$ (Fig. 2), whereas up to a 2 -fold change was observed for viscosity (Fig. 1).

$\eta_{r}-H_{T}$ interrelations. Several investigators $(12,29,30)$ have shown that $R B C$ suspensions flowing in large geometries behave as homogeneous fluids, and that the magnitude of suspension viscosity is primarily determined by hematocrit. For RBC flowing in small-diameter tubes, it is traditionally accepted that because the reduction of viscosity with decreasing tube diameter is also accompanied by a reduction in $\mathrm{H}_{\mathrm{T}}$, the FLE is due to the FE (29). Barbee and Cokelet (4) have indicated that knowledge of $\mathrm{H}_{\mathrm{T}}$, combined with viscosity data obtained in large tubes where $\mathrm{H}_{\mathrm{T}}=\mathrm{H}_{\mathrm{F}}$, allowed accurate prediction of viscosities for both normal and fixed cells in tubes as small as $29 \mu \mathrm{m}$. However, the $\mathrm{H}_{\mathrm{T}}$ data of Barbee and Cokelet (5) and Cokelet (29) for adult cells differ markedly from other literature reports $(2,3,7,19)$; further, our more recent results $(20.26)$ at $\mathrm{H}_{\mathrm{F}}$ from 0.40 to 0.57 $\mathrm{L} / \mathrm{L}(40$ to $57 \%)$ in narrow tubes indicate that their suggestion is invalid for isotonic and nonisotonic adult $R B C$ suspensions. To our knowledge, there are no published data relevant to the $\mathrm{FE}$ for neonatal RBC. Thus, to examine $\eta_{\mathrm{r}}-\mathrm{H}_{\mathrm{T}}$ relations for the data obtained for neonatal RBC suspensions in the present study, values of $\eta_{\mathrm{r}}$ and $\mathrm{H}_{\mathrm{T}}$ were replotted, at $\mathrm{V} / \mathrm{V}_{\text {iso }}=0.80$ and 1.00 , from the curves presented in Figures 1 and $2: \mathrm{H}_{\mathrm{T}}$ values were determined by using interpolated $\mathrm{H}_{\mathrm{T}} / \mathrm{H}_{\mathrm{F}}$ values multiplied by the mean $\mathrm{H}_{\mathrm{F}}$ [i.e. $\left.\mathrm{H}_{\mathrm{T}}=\left(\mathrm{H}_{\mathrm{T}} / \mathrm{H}_{\mathrm{F}}\right)(0.401 \mathrm{~L} / \mathrm{L} \times 100 \%)\right]$.

The $\eta_{\mathrm{r}}-\mathrm{H}_{\mathrm{F}}$ data resulting from the above interpolation procedure are shown in Figure 3 for neonatal RBC suspensions at $\mathrm{V} / \mathrm{V}_{\text {iso }}=0.80$ and 1.00 , and for adult cell suspensions at $\mathrm{V} / \mathrm{V}_{\text {iso }}$ $=0.80,1.00$, and 1.22; the solid lines connecting the data points of constant $\mathrm{V} / \mathrm{V}_{\text {iso }}$ were obtained by linear regression. Also shown are representative data obtained in $340-\mu \mathrm{m}$ tubes for neonatal $\mathrm{RBC}$ with $\mathrm{V} / \mathrm{V}_{\text {iso }}$ of 0.80 and 1.00 . Because $\mathrm{H}_{\mathrm{T}}=\mathrm{H}_{\mathrm{F}}$ in these 340- $\mu \mathrm{m}$ tubes, variations in $\mathrm{H}_{\mathrm{T}}$ were obtained via changes in $\mathrm{H}_{\mathrm{F}}$.

As can be seen in Figure 3, $\eta_{\mathrm{r}}$ rose linearly with increasing $\mathrm{H}_{\mathrm{T}}$ for both neonatal and adult $\mathrm{RBC}$ over the range of $\mathrm{V} / \mathrm{V}_{\text {iso }}$ studied, thus producing a family of lines whose vertical placement was inversely related to $V / V_{\text {iso }}$ : the lower the value of $V / V_{\text {iso }}$, the higher the line. The sensitivity of $\eta_{r}$ to $\mathrm{H}_{\mathrm{T}}$ for both cell types also increased markedly with decreasing $\mathrm{V} / \mathrm{V}_{\text {iso. }}$. For example, at $\mathrm{V} / \mathrm{V}_{\text {iso }}=0.80$, neonatal and adult $\mathrm{RBC}$ had a slope 2.6 times greater than neonatal and adult cells at $\mathrm{V} / \mathrm{V}_{\text {iso }}=1.00$; in contrast, at $\mathrm{V} / \mathrm{V}_{\text {iso }}=1.22$ adult cells had a $47 \%$ lower slope compared with the equivolumic, isotonic neonatal $\mathrm{RBC}$. The close grouping of the $\eta_{\mathrm{r}}-\mathrm{H}_{\mathrm{T}}$ data at constant $\mathrm{V} / \mathrm{V}_{\text {iso }}$ was thus independent of RBC type.

Disparities in the $\eta_{\mathrm{r}}-\mathrm{H}_{\mathrm{T}}$ data for the neonatal RBC suspensions were also observed between the small tubes and the larger, 340$\mu \mathrm{m}$ diameter tubes (Fig. 3). For both $\mathrm{V} / \mathrm{V}_{\text {iso }}=0.80$ and 1.00 , the values of $\eta_{r}$ are only in agreement for the $146-\mu \mathrm{m}$ tubes (highest neonatal points on the solid lines), whereas maximal disagreement in $\eta_{\tau}$ (47\% lower) was obtained in $32-\mu \mathrm{m}$ versus $340-\mu \mathrm{m}$ tubes for hypertonic neonatal $\mathrm{RBC}$ at an $\mathrm{H}_{\mathrm{T}}$ of $33 \%$. These results, together with our previous reports for adult $\mathrm{RBC}$ suspensions $(20,26)$, therefore contradict the suggestion (4) that the 


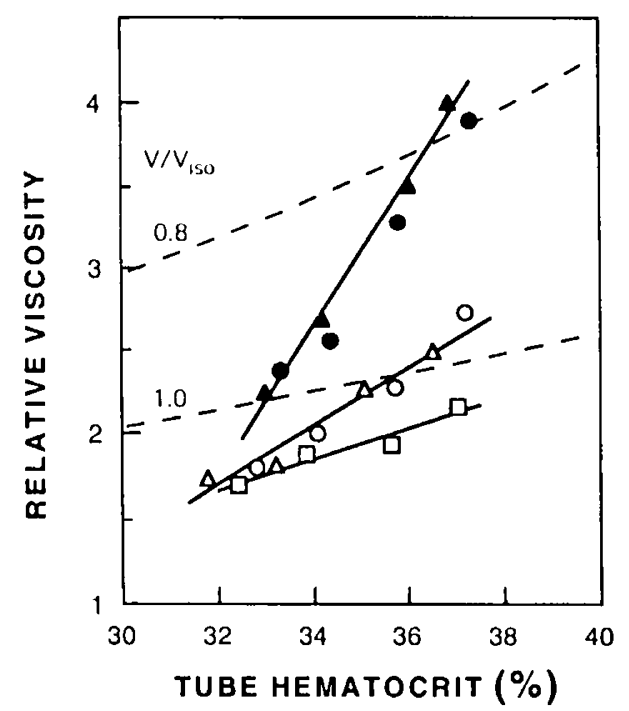

Fig. 3. The $\eta_{\mathrm{r}}-\mathrm{H}_{\mathrm{T}}$ data for neonatal $\mathrm{RBC}$ at $\mathrm{V} / \mathrm{V}_{\text {iso }}=0.80$ and 1.00 , and for adult $\mathrm{RBC}$ at $\mathrm{V} / \mathrm{V}_{\text {iso }}=0.80,1.00$, and 1.22: symbols are identical to those used in Figures 1 and 2 . Note that tube diameter does not appear explicitly: however, the data points with the highest $\mathrm{H}_{\mathrm{T}}$ correspond to $145-\mu \mathrm{m}$ tubes and the lowest to $32-\mu \mathrm{m}$ tubes; $46-$ and $86-\mu \mathrm{m}$ data are located between these extremes (Fig. 2). Dashed lines represent regressions of the form $y=a+b x+c^{2}$ for neonatal $R B C$ in hypertonic and isotonic media obtained in $340-\mu \mathrm{m}$ tubes with $\mathrm{H}_{\mathrm{T}}$ from 20 to $60 \%(0.40$ to $0.60 \mathrm{~L} / \mathrm{L} \times 100 \%$ ) (see text).

viscosity of $\mathrm{RBC}$ suspensions in small tubes is uniquely determined by $H_{T}$. Furthermore, the nonsymmetric effects of $V / V_{\text {iso }}$ on the $\eta_{\mathrm{r}}-\mathrm{H}_{\mathrm{T}}$ relations suggest alternative methods of analysis for these data.

Prediction of $\eta_{r}$ : neonatal versus adult $R B C$. Using a parametric equation, McKay and Meiselman $(20,26)$ have suggested that the $\eta_{\mathrm{r}}$ of adult RBC suspensions at various osmolalities could be explained by considering the unequal number concentration of cells $\left(\right.$ i.e. $\left.\mathrm{H}_{\mathrm{T}} / \mathrm{V}\right)$ in the tube and a scaling term $\ln (\mathrm{KD} / \mathrm{V})$, which is an expression of the size of the tube relative to the $\mathrm{RBC}$. This possibility was therefore examined for neonatal RBC. Note that the scaling term, when multiplied by $\mathrm{RBC}$ number concentration, generates an independent variable $\mathrm{H}^{\prime}=\left(\mathrm{H}_{\mathrm{T}} / \mathrm{V}\right) \ln (\mathrm{KD} / \mathrm{V})$. The $\eta_{\mathrm{r}}-\mathrm{H}_{\mathrm{T}}$ data in Figure 3 were thus compared with the equation $(20,26) \eta_{\mathrm{r}}=\exp \left(\mathrm{A} \mathrm{H}^{\prime}\right)$, with $\mathrm{A}=0.52(20)$ and with $\mathrm{K}$ assigned a value of 90 (i.e. the nominal isotonic adult $\mathrm{RBC}$ volume in $\mathrm{fL})$. As shown in Figure $4 A$, this analysis agreed well with the adult RBC data (lower curve, rms error variance of 0.021 ), whereas the neonatal RBC data clearly do not fit the equation. However, by using $\mathrm{A}=0.66$ and $\mathrm{K}=108$ (i.e. the nominal isotonic neonatal $\mathrm{RBC}$ volume), the equation showed good agreement with the neonatal data (upper curve, rms error variance of 0.082).

In the above-mentioned discussion of the two computed lines shown in Figure $4 A$, the constant $\mathrm{A}$ in the equation $\eta_{\mathrm{r}}=\exp (\mathrm{A}$ $\left.H^{\prime}\right)$ varied in proportion to the isotonic volume of the respective cell type. A more generalized approach is thus to let $A=V_{\text {iso }}$ and to also let $\mathrm{K}=\mathrm{V}_{\text {iso }}$; such a procedure therefore generates a new independent variable $\mathrm{H}_{\mathrm{T}}\left(\mathrm{V}_{\text {iso }} / \mathrm{V}\right) \cdot \ln \left(\mathrm{DV}_{\text {iso }} / \mathrm{V}\right)$. The $\eta_{\mathrm{r}}$ data versus this new variable are shown in Figure $4 B$, where it can be seen that the use of this new term greatly reduces the dispersion of the data (rms error variance of 0.039 for all data shown).

The data in Figure 3 were also compared with a Krieger-type equation (31) that has been previously modified to describe the viscometric behavior of different adult $\mathrm{RBC}$ in narrow tubes $(20$, 26):

$$
\eta_{\mathrm{r}}=1.08\left(1-\mathrm{GH}_{\mathrm{T}}\right)^{-4.50}
$$

where $\mathrm{G}=0.00105\left(\mathrm{~V}_{\text {iso }} / \mathrm{V}\right) \ln \left(\mathrm{DV}_{\text {iso }} / \mathrm{V}\right)$. Figure $4 B$ shows the
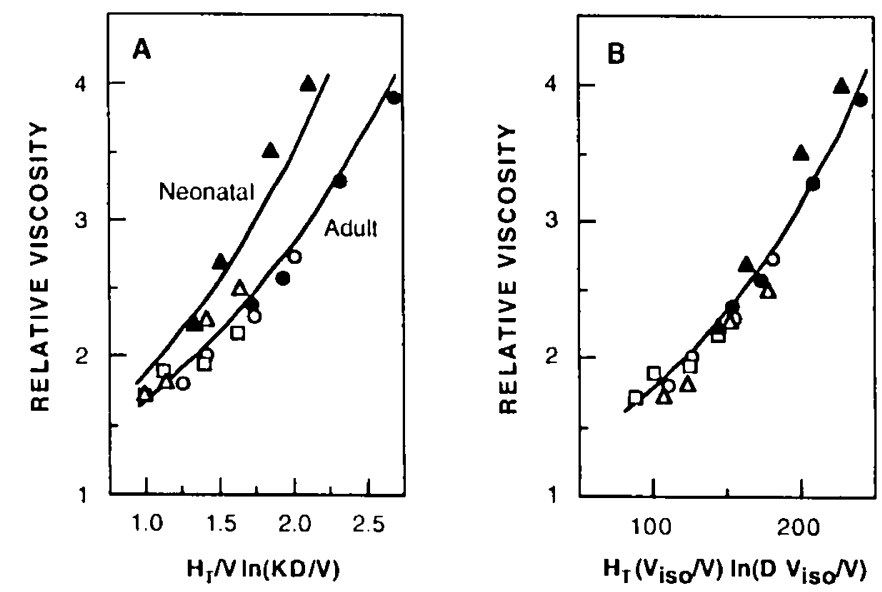

Fig. 4. Two approaches to the interrelations between $\eta_{r}$ and $H_{T}$ : viscosity and $\mathrm{H}_{\mathrm{T}}$ data and symbols are identical to those shown in Figures 1 and $2 . A, \eta_{\mathrm{r}} v s$ number of RBC per unit volume of suspension in the tube (i.e. $\left.\mathrm{H}_{\mathrm{T}} / \mathrm{V}\right)$ multiplied by a scaling term [i.e. $\left.\ln (\mathrm{KD} / \mathrm{V})\right]$. Both curves are calculated from the equation $\eta_{\mathrm{r}}=\exp \left(\mathrm{A} \mathrm{H}^{\prime}\right)$, where $\mathrm{A}=0.66$ and $\mathrm{K}$ $=108$ for neonatal $\mathrm{RBC}$ (upper curve) and $\mathrm{A}=0.52$ and $\mathrm{K}=90$ for adult RBC (lower curve). $B, \eta_{\mathrm{r}}$ is new independent variable $\mathrm{H}_{\mathrm{T}}\left(\mathrm{V}_{\mathrm{iso}} / \mathrm{V}\right)$ $\ln \left(D V_{\text {iso }} / V\right)$, where $V_{\text {iso }}=108$ or 90 for neonatal or adult $R B C, D$ is tube diameter, and $V$ is $R B C$ volume. The curve was obtained by least squares fitting of the data to a parametric equation (31) for latex spheres (see text).

fit was satisfactory for both the neonatal and adult $\mathrm{RBC}$ data (rms error variance of 0.027 ). The excellent agreement of both the $\mathrm{AH}^{\prime}$ and Krieger equations with the data therefore indicates their usefulness for both neonatal and adult RBC over the entire experimental range of tube diameters ( 32 to $146 \mu \mathrm{m})$ and suspending media osmolalities. Thus, the term $V_{\text {iso }} / \mathrm{V}$, which is a determinant of cellular deformability $(12,16)$, and the geometric scaling term $\ln \left(\mathrm{DV}_{\text {iso }} / \mathrm{V}\right)$ together yield an effective hematocrit for both red cell types when multiplied by $\mathrm{H}_{\mathrm{T}}$. The close correlation between $\eta_{\mathrm{r}}$ and this effective hematocrit (i.e. Fig. $4 B$ ), combined with the congruency of the viscosity data and the Krieger equation, are of particular interest in that they suggest that both RBC deformability and size (i.e. volume) are of major importance in determining overall suspension flow behavior in narrow tubes for both neonatal and adult RBC. Although the semiempirical nature of our effective hematocrit method is acknowledged, this approach, previously found $(20,26)$ applicable to $\mathrm{H}_{\mathrm{F}}=0.40-0.57 \mathrm{~L} / \mathrm{L}(40-57 \%)$ adult $\mathrm{RBC}$ suspensions in narrow tubes $(32-146 \mu \mathrm{m})$, can now be extended to $0.40 \mathrm{~L} / \mathrm{L}$ $(40 \%) \mathrm{H}_{\mathrm{F}}$ suspensions of neonatal RBC. Our model should thus be useful in predicting in situ viscosity from in vivo microhemodynamic data (e.g. vessel diameter and vessel hematocrit, D and $\mathrm{H}_{\mathrm{T}}$ ) in the neonatal and developed microcirculation, and may be particularly useful for the prediction of blood viscosity at high osmolality (e.g. in renal vasa recta). Of course, for nonisotonic regions of the microcirculation, it is necessary to know the actual RBC volume (V), where $V$ is determined by the local plasma osmolality; micropipette sampling of plasma, combined with the $\mathrm{V} / \mathrm{V}_{\text {iso }}$ equation presented in Materials and Methods, would be one approach to the estimation of V. Further refinement of our model and comparisons to experimental data should aid in defining the merits and limits of this approach.

In summary, the present results extend our prior viscosity and $\mathrm{H}_{\mathrm{T}}$ data $(20,26)$ to isotonic and nonisotonic suspensions of neonatal $\mathrm{RBC}$ in narrow-diameter tubes. These data, together with our previous reports, serve to describe the role of neonatal and adult red cell volume, and cellular deformability, on the flow behavior of RBC suspensions in narrow tubes. However, complete evaluation may require additional experiments using more realistic geometries of the in vivo microcirculation (e.g. 32). 
Our results should also provide an in vitro data base for describing blood flow in hypertonic regions of the circulation (e.g. renal vasa recta) and in hypernaturemic dehydration, and for estimating flow resistance of pathologic RBC with altered volumes or abnormal cellular properties (e.g. sickle cells, hereditary spherocytosis) in the developing and mature microcirculation. Although it is acknowledged that our present data and model do not consider normal in vivo flow control mechanisms (i.e. vasodilation or vasoconstriction) that could possibly compensate for the observed viscosity differences, it appears likely that viscosity reduction in narrow vessels is similar to that in narrow tubes $(9,25)$. Our current results indicate that the viscosity reduction is more pronounced for neonatal $\mathrm{RBC}$; even greater reductions have been reported at higher feed hematocrits (25). Because the product of tube or vessel discharge hematocrit $x$ volumetric blood flow rate is proportional to oxygen delivery through a microvessel $(8,20,26)$, the enhanced viscosity reduction of neonatal $\mathrm{RBC}$ in narrow vessels may be important in adequate circulation and oxygen delivery in the neonate.

Acknowledgments. The authors thank Mandy Jackson, Victoria Lovelace, and Rosalinda Wenby for their technical assistance.

\section{REFERENCES}

1. Chien S 1975 Biophysical behavior of red cells in suspension. In: Surgenor DM (eds) Biophysical Behavior of Red Cells in Suspension. Academic Press. New York, pp 1031-1133

2. Gaehtgens P 1981 Distribution of flow and red cell flux in the microcirculation. Scand J Clin Lab Invest 41:83-87

3. Azelvandre F, Oiknine C 1976 Effet Fähraeus et effet Fähraeus-Lindqvist: resultats experimentaux et modeles theoriques. Biorheol 13:325-335

4. Barbee JH. Cokelet GR 1971 Prediction of blood flow in tubes with diameters as small as $29 \mu \mathrm{m}$. Microvasc Res 3:17-21

5. Barbee JH, Cokelet GR 1971 The Fähraeus effect. Microvasc Res 3:6-16

6. Gaehtgens P. Albrecht KH, Kreutz F 1978 Fähraeus effect and cell screening during tube flow of human blood. I. Effect of variation of flow rate. Biorheol 15:147-154

7. Gupta BB. Seshadri V 1977 Flow of red blood cell suspensions through narrow tubes. Biorheol 14:133-143

8. Goldsmith HL, Cokelet GR, Gaehtgens P 1989 Robin Fähraeus: evolution of his concepts in cardiovascular physiology. Am J Physiol 257:H1005-H1015

9. Pries AR. Neuhaus D. Gaehtgens $P 1992$ Blood viscosity in tube flow: dependence on diameter and hematocrit. Am J Physiol 263:H1770-H1778
10. Fähraeus R. Lindqvist T 1931 The viscosity of blood in narrow capillary tubes. Am J Physiol 96:562-568

11. Fåhraeus R 1929 The suspension stability of the blood. Physiol Rev 9:241274

12. Cokelet GR, Meiselman HJ, Brooks D 1980 Erythrocyte Mechanics and Blood Flow. AR Liss Co. New York

13. Braasch D, Jenett W 1968 RBC flexibility, hemoconcentration and friction resistance in capillaries. Pflügers Arch 302:245-254

14. Reinhart WH, Chien S 1985 Roles of cell geometry and cellular viscosity in red cell passage through narrow pores. Am J Physiol 248:C473-C479

15. Meiselman HJ 1978 Rheological behavior of shape-transformed human red cells. Biorheol 15:225-237

16. Meiselman HJ 1981 Morphological determinants of red cell deformability. Scand J Clin Lab Invest 41:27-34

17. Nash GB. Meiselman HJ 1991 Effect of dehydration on the viscoelastic behavior of red cells. Blood Cells 17:517-522

18. McKay CB 1980 Etude de l'effet de la deformabilite erythrocytaire sur les proprietes rheologiques de suspensions d'hematies dans des capillaires de 30 a $500 \mu \mathrm{m}$. Ph.D. thesis, University de Technologie, Compiegne, France

19. Seshadri V. McKay CB, Jaffrin M 1979 Effect of RBC flexibility on blood flow through tubes with diameters 30 to $500 \mu \mathrm{m}$. Biorheol 16:473-483

20. McKay CB. Meiselman HJ 1988 Osmolality-mediated Fåhraeus and FåhraeusLindqvist effects for human RBC suspensions. Am J Physiol 254:H238H249

21. Linderkamp O, Nash GB. Meiselman HJ. Wu PYK 1986 Deformability and intrinsic material properties of neonatal red blood cells. Blood 67:1244-1250

22. Linderkamp O, Wu PYK, Meiselman HJ 1983 Geometry of neonatal and adult red blood cells. Pediatr Res 17:250-253

23. Linderkamp O, Meiselman HJ, Wu PYK. Miller FC 1981 Blood and plasma viscosity and optimal hematocrit in the normal newborn infant. Clin Hemorheol 1:575-584

24. Reinhart WH 1985 Rheology of fetal and maternal blood. Pediatr Res 19:147153

25. Zilow EP, Linderkamp O 1989 Viscosity reduction of red blood cells from preterm and full term and adults in narrow tubes (Fảhraeus-Lindqvist effect). Pediatr Res 25:595-599

26. McKay CB, Meiselman HJ 1989 Osmolality- and hematocrit-mediated flow behavior of RBC suspensions in 33 $\mu \mathrm{m}$ ID tubes. Biorheol 26:863-874

27. Wilkinson WL 1960 Non-Newtonian Fluids. Pergamon Press. New York

28. Müller GH. Schmid-Schönbein H. Meiselman HJ 1992 Development of viscoelasticity in heated hemoglobin solutions. Biorheol 29:203-216

29. Cokelet GR 1976 Blood rheology interpreted through flow properties of the red cell. In: Grayson J, Zingg W (eds) Blood Rheology Interpreted Through Flow Properties of the Red Cell. Plenum Publishers, New York, pp 9-31

30. Lowe GDO 1988 Clinical Blood Rheology. CRC Press, Boca Raton. FL

31. Krieger IM 1972 Rheology of monodisperse lattices. Adv Coll Interf Sci 3: $111-136$

32. McKay CB. Lipowsky HH 1988 Arteriovenous distribution of transit times in cremaster muscle of the rat. Microvasc Res 36:75-91 